\title{
The placenta: transcriptional, epigenetic, and physiological integration during development
}

\author{
Emin Maltepe,1,2,3,4 Anna I. Bakardjiev,1,2,5 and Susan J. Fisher 2,3,4,6,7
}

\author{
${ }^{1}$ Department of Pediatrics, ${ }^{2}$ Biomedical Sciences Program, ${ }^{3}$ Center for Reproductive Sciences and the Department of Obstetrics, \\ Gynecology and Reproductive Sciences, ${ }^{4}$ Eli and Edythe Broad Center for Regeneration Medicine and Stem Cell Research, \\ ${ }^{5}$ Program in Microbial Pathogenesis and Host Defense, ${ }^{6}$ Department of Anatomy, and \\ ${ }^{7}$ Human Embryonic Stem Cell Program, University of California, San Francisco.
}

\begin{abstract}
The placenta provides critical transport functions between the maternal and fetal circulations during intrauterine development. Formation of this interface relies on coordinated interactions among transcriptional, epigenetic, and environmental factors. Here we describe these mechanisms in the context of the differentiation of placental cells (trophoblasts) and synthesize current knowledge about how they interact to generate a functional placenta. Developing an understanding of these pathways contributes to an improvement of our models for studying trophoblast biology and sheds light on the etiology of pregnancy complications and the in utero programming of adult diseases.
\end{abstract}

Infants born before the 37 th week of gestation are considered premature, and their care places an enormous burden on the health care infrastructure. In developed countries such as the United States, preterm delivery accounts for approximately $10 \%-13 \%$ of all deliveries (1). Despite advances in our understanding of the risk factors associated with preterm delivery, the rate has risen over the past 2 decades, due in large part to parallel increases in indicated preterm deliveries (1). In developed countries, iatrogenic delivery is responsible for almost half the births that occur between the 28th and 37 th weeks of gestation. These are due mostly to placental pathologies such as preeclampsia, in which a dramatic increase in maternal blood pressure is accompanied by excess protein in the maternal urine and signs of maternal vascular damage. If untreated, the syndrome can lead to maternal seizures.

Along with the rise in preterm delivery rates, the survival of preterm infants has increased due to medical and technological advances (2). This convergence has resulted in a greatly expanded population of patients admitted to and graduating from intensive care nurseries, placing ever-greater emotional and economic demands on society. Not only are these infants more likely than their counterparts born at term to develop complications such as bronchopulmonary dysplasia, failure to thrive, pulmonary hypertension, cerebral palsy, and blindness, but they are also more likely to develop chronic adult ailments such as diabetes and heart disease (3). This increased risk stems in part from the fact that environmental insults incurred in utero can result in long-lasting increases in disease susceptibility via a process known as fetal programming. However, dramatic changes in the fetal environment as a result of premature birth can also result in an increased risk, later in life, of cardiovascular disease and diabetes (4). While further improvements in neonatal care are critical for diminishing the long-term consequences of prematurity, prevention or delay of preterm delivery will have the greatest health care impact for this at-risk population. A better understanding of the most common placental pathologies, such as those associated with preeclampsia and/or intrauterine growth restriction, is therefore of paramount importance for advancing maternal, fetal, and adult medicine.

The placenta is a remarkable organ. Short lived by design, its brief existence enables the mammalian embryo/fetus to survive

Conflict of interest: The authors have declared that no conflict of interest exists. Citation for this article: J Clin Invest. 2010;120(4):1016-1025. doi:10.1172/JCI41211. within the confines of the intrauterine environment. The diversity of functions performed by the placenta is impressive, ranging from anchoring the conceptus and preventing its rejection by the maternal immune system to enabling the transport of nutrients and wastes between the mother and the embryo/fetus. As with all organs, it performs these functions via multiple specialized cell types derived from lineage-committed precursors that either proliferate or differentiate. This process depends on a coordinated interaction among genetic, epigenetic, and physiological cues that are differentially interpreted as a function of gestational age. Each developmental event leading to the formation of a mature placenta is contingent upon the conditional transformation of prior structures. Developmental information, therefore, has its own history, i.e., an "ontogeny of information," that includes changes in the environment over time as an important variable (5).

The placenta is a chimeric organ containing both maternal and fetal structures (Figure 1). While placental cells (trophoblasts) initially proliferate much more rapidly than the embryo following implantation (6), formation of the maternal-fetal interface and subsequent oxygen and nutrient transport result in a 40 -fold increase in the fetus/placenta weight ratio in humans at term (7). This feat is accomplished by a massive increase in placental transport capacity due to a diverse set of developmental processes, including branching and nonbranching angiogenesis, branching morphogenesis, and trophoblast differentiation into several cell types, including invasive cytotrophoblasts (iCTBs) and multinucleated syncytiotrophoblasts (SynTs). The bulk of our knowledge regarding the development of the human placenta stems from analysis of this organ following pregnancy termination or premature delivery. Additionally, animal models such as the mouse have proven invaluable for deciphering the molecular mechanisms responsible for placentation as well as the earliest events in establishing the trophoblast lineage. Although there are some structural and functional differences between human and mouse placentas (Figure 1, A-C vs. D-E, respectively), we can still use information gleaned from the mouse to understand the molecular underpinnings of human placentation and the defects in this process that are associated with pregnancy disorders. For example, while it was once assumed that preeclampsia was primarily a human malady, it is now possible to model this disease in rodents (8-13).

A great deal is known about the many determinants that specify trophoblast differentiation and placental development. Here we 
A
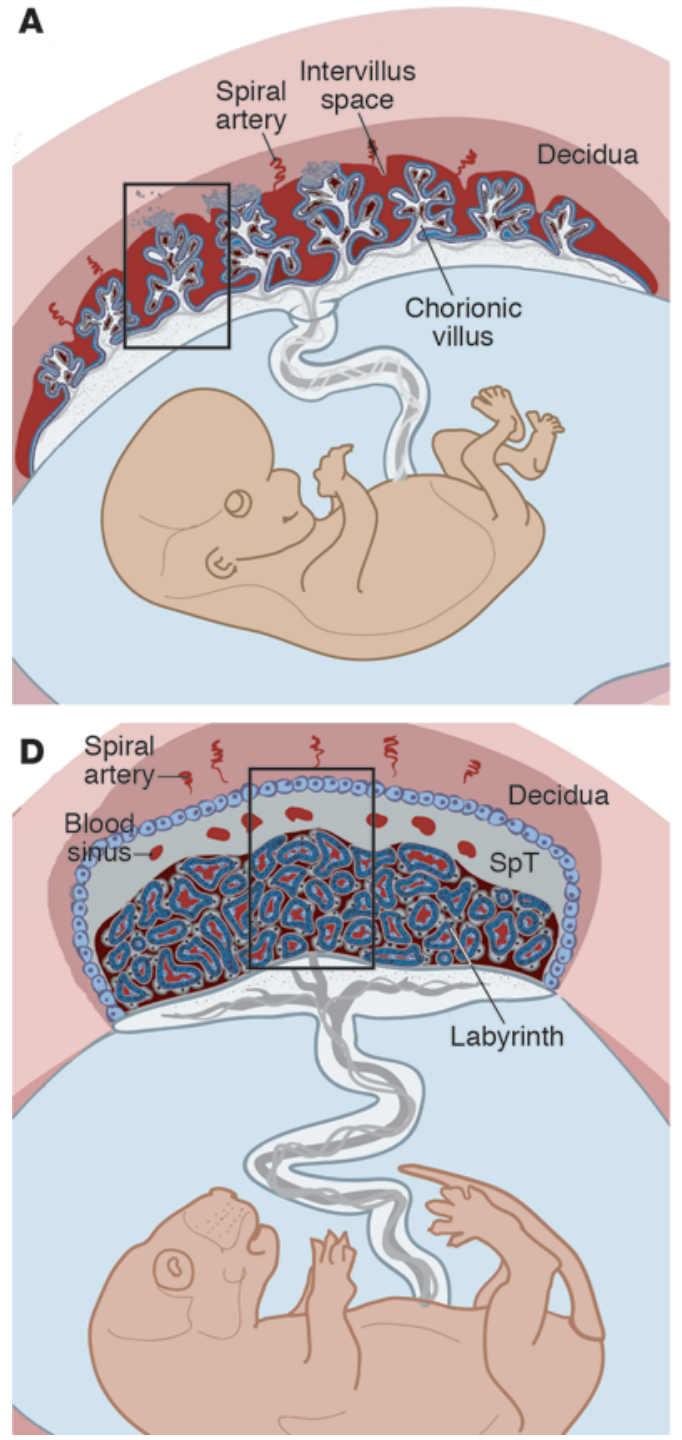

B
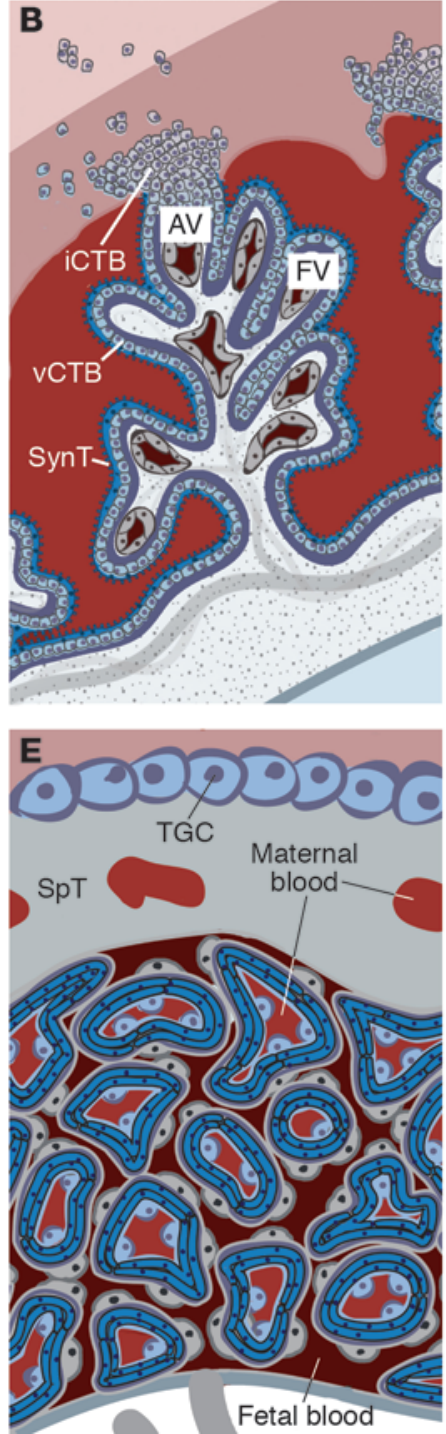

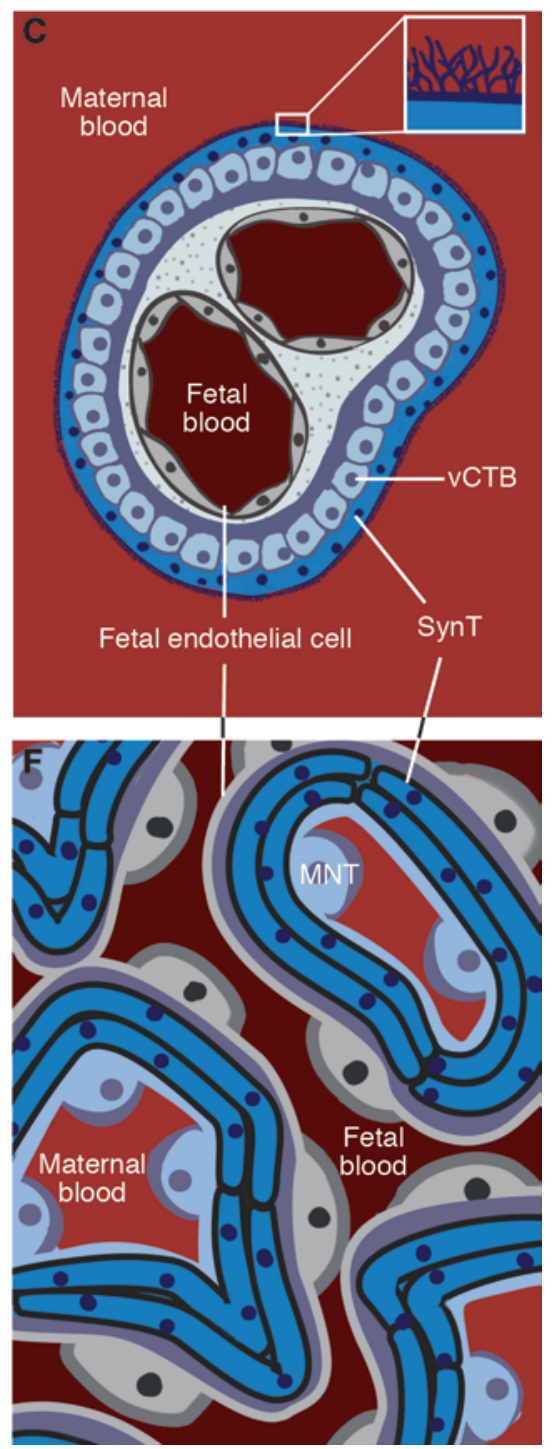

Figure 1

Comparative anatomy of human and mouse placentas. Placentation is categorized by the relationship between trophoblasts and the maternal cells/ tissues with which they come into contact. In the hemochorial placentas of humans (A-C) and mice (D-F), the maternal vessels are invaded and colonized by invasive trophoblasts (not shown). (A) Consequently, in humans, decidual spiral arterioles perfuse the chorionic villi that line the intervillous space (adapted from PLoS Pathogens; ref. 158). (B) In floating villi (FV), a continuous layer of multinucleated SynT interfaces with maternal blood. Beneath lies a progenitor population of mononuclear vCTB. At the uterine wall, iCTBs differentiate along the invasive pathway to form anchoring villi (AV). A subset of iCTBs breaches spiral arterioles and differentiates into an endovascular subtype that replaces the resident maternal endothelium (not shown). (C) The cross-sectional anatomy of a floating villus shows that the apical surfaces of SynTs are covered with branched microvilli that maximize their surface areas for gas and nutrient/waste exchange. The blood vessels that ramify through the villous stroma carry embryonic/fetal blood. (D) In mice, maternal blood from decidual spiral arterioles flows through blood sinuses in the SpT layer to reach the labyrinth. (E) TGCs, like iCTBs, anchor the placenta to the uterus and invade the spiral arterioles (not shown). (F) In mice, maternal blood is in direct contact with a layer of mononuclear trophoblasts (MNTs, also known as S-TGCs) that is surrounded by a bilayer of SynTs, which are in close proximity to fetal capillaries.

concentrate specifically on the intersection between transcriptional, epigenetic, and physiological factors in specifying placental cell fate. Pregnancy complications such as preeclampsia and intrauterine growth restriction are thought to arise, at least in part, from aberrations of transcriptional responses to physiological stimuli such as hypoxia (14). Additionally, fetal programming mechanisms depend on the interplay of transcriptional and epigenetic regulators with environmental cues to induce alterations that manifest as disease susceptibility in adults (15). In this context, a greater understanding of the integrating mechanisms will yield important insights into how this newly appreciated phenomenon translates into clinical pathology during adulthood.

\section{Transcriptional regulation of trophoblast fate}

Early lineage restriction within the blastocyst. In mice, establishment of the extraembryonic lineages is considered the first differentiation step during early embryonic development. Following compaction (an increase in intercellular adhesion that causes all the cells to 


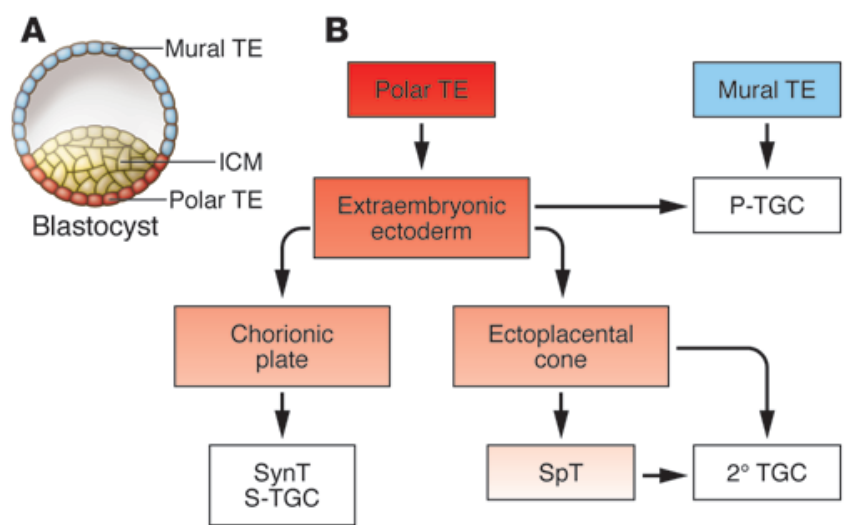

\section{Figure 2}

Lineage segregation within the mouse blastocyst and early placenta. (A) At day E3.5, the blastocyst comprises an outer TE destined to populate the placenta and an ICM destined to form the embryo. TE cells not in direct contact with the ICM form the mural TE, whereas those adjacent to the ICM form the polar TE. The polar TE gives rise to the ExE, from which TS cells can be derived in vitro. (B) Following implantation, mural TEs initiate the first wave of TGC differentiation to form $1^{\circ} \mathrm{TGCs}$, which contribute directly to the P-TGC population. Cells within the polar TE continue to proliferate and populate the ExE. Some $2^{\circ} \mathrm{TGCs}$ arise directly from the ExE. Along with $1^{\circ} \mathrm{TGCs}$, they compose the P-TGC population that lines the implantation site. Cells within the ExE then differentiate to form the chorionic plate and the EPC. The chorionic plate is responsible for populating the mouse labyrinth with SynTs and a subset of $2^{\circ}$ TGCs called S-TGCs. Together, these cells are responsible for the transport functions of the placenta. Cells within the EPC can either differentiate into a population of lineage-committed progenitors known as SpTs, which then differentiate into $2^{\circ} \mathrm{TGCs}$, or they can directly differentiate into various $2^{\circ}$ TGCs subtypes.

adopt a more flattened morphology), two distinct cell populations are created. The outer layer, termed the trophectoderm (TE), exhibits features of polarized epithelia, with apical microvilli and the asymmetric distribution of tight and adherens junctions (Figure 2). The component cells give rise to the placenta (reviewed in ref. 16). An underlying aggregate of irregular nonpolarized cells forms the inner cell mass (ICM). TE cells in direct contact with the ICM, the polar TE, give rise to trophoblast stem (TS) cells in vitro and populate the major structures of the placenta in vivo (Figure 2). The ICM ultimately gives rise to the embryo proper (in vivo) or ES cells (in vitro). Studies in the mouse have revealed the critical importance of a set of lineage-restricted transcription factors for the establishment, maintenance, and pluripotency of ES cell identity (Figure 3): octamer 3/4 (OCT4) (17), SRY-box-containing gene 2 (SOX2) (18), NANOG (19), sal-like protein 4 (SALL4) (20), and Krüppel-like factor 4 (KLF4) (21). This list is not likely to be exhaustive because various sets of transcription factors can induce pluripotency in differentiated cell types (22).

Extraembryonic development also depends on a unique subset of transcriptional regulators (Figure 3). Expression of the Drosophila caudal-related transcription factor $C d x 2$ is restricted in mice to the TE; its overexpression in mouse ES cells results in the adoption of TE cell fates (23), while its absence results in embryos lacking TE-to-trophoblast differentiation (24). Therefore, while CDX2 is not critical for initially specifying the TE, it is nevertheless required for its maintenance and subsequent differentiation.
Specification of the TE in mice also requires the transcription factor TEA-domain family member 4 (TEAD4). Tead4 $4^{-/}$embryos die at the peri-implantation stage and fail to form a blastocoel - the fluid-filled cavity inside the early embryo that is essential for formation of the three embryonic germ layers $(25,26)$. In these embryos, $C d x 2$ expression is lost after the morula stage and the entire conceptus consists of ICM derivatives with ubiquitous Oct4 and Nanog expression. Consistent with their critical role in establishing TE cell fates, TS cells cannot be isolated from these embryos, while ES cells can. Unlike Cdx2, Tead4 expression is not restricted to the TE, suggesting that other lineage-specific factors, such as Yes-associated protein 1 (Yap1; also known as Yap) (27-29), may cooperate with TEAD4 to produce the observed effects on TE specification. After TEAD4 and CDX2, the product of the T-box gene eomesodermin homolog (Eomes) is the earliest acting transcription factor known to be required for key postimplantation lineage commitment steps, and mice lacking Eomes gene expression fail to exhibit proper TE-to-trophoblast differentiation (30). Although implantation does occur, the conceptus arrests at a blastocyst-like stage of development (30).

Following implantation in mice, TE cells not in direct contact with the ICM (i.e., the TE cells that form the mural TE) differentiate into primary trophoblast giant cells $\left(1^{\circ} \mathrm{TGC}\right)$ that may be analogous to iCTBs in humans (Figures 1 and 2). Unlike secondary TGCs ( $2^{\circ}$ TGCs), which arise from the polar TE and frequently pass through a spongiotrophoblast (SpT) stage of development (Figure 2 ), $1^{\circ}$ TGCs arise directly from the mural TE. $1^{\circ}$ and $2^{\circ}$ TGCs together compose the parietal TGC (P-TGC) population that anchors the placenta to the uterus and engages in the remodeling of maternal vasculature critical for establishing blood flow to the placenta (Figure 1). TGCs and iCTBs undergo a fascinating process of DNA replication without intervening mitoses (endoreplication), resulting in the formation of highly polyploid cells (reviewed in ref. 31). Some of the molecular mechanisms regulating this process are beginning to be understood. For example, mouse embryos lacking the cell-cycle regulatory protein Geminin contain only polyploid TE and fail to express OCT4 at the blastocyst stage of development (32). Geminin, which is detected as early as the 8-cell stage, had previously been determined to regulate ploidy in cancer cells via its role in replication licensing (33-35). Geminin is downregulated during the S- and G-like phases of endoreplicating TGCs via proteasome-mediated degradation (32). Cyclin $\mathrm{E}$ is also required for proper endoreplication in mice, and deficient cyclin E activity results in embryonic lethality due to impaired placentation (36, 37). Therefore, early lineage specification in the mouse blastocyst depends on the proper regulation of cell ploidy. Consistent with this observation, the formation of tetraploid mouse embryos following electrofusion of late 2-cell-stage embryos (38) results in the formation of cells that are largely restricted in their developmental potential to the TE (39), although some early embryonic contribution has also been noted (40). Thus, absolute DNA content can direct cell fate, restricting early differentiation to short-lived extraembryonic structures when deviations from diploidy are detected. In line with these observations, human trophoblast cells exhibit remarkable genetic heterogeneity at the chromosomal level (41).

The interdependence of placental cell fates. Unlike the mural TE, which immediately differentiates into postmitotic $1^{\circ}$ TGCs that contribute directly to the P-TGC population, the polar TE continues to proliferate and gives rise to diploid cells that comprise the extraembryonic ectoderm (ExE). Precursors within the ExE 


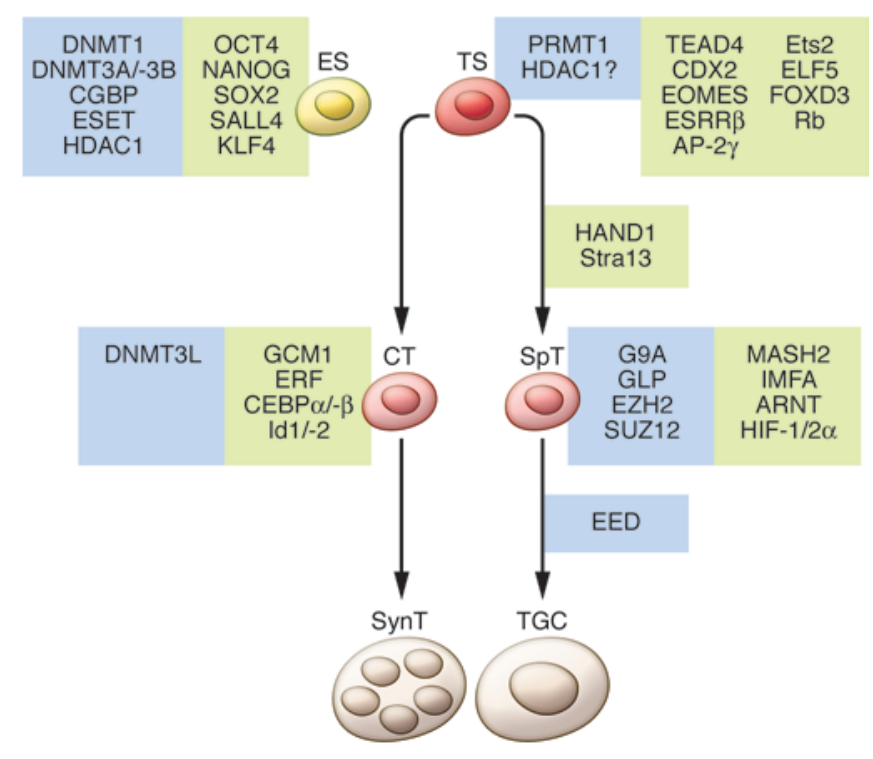

proliferate to generate the chorionic plate as well as the ectoplacental cone (EPC) (reviewed in ref. 31). The EPC is itself a stem cell compartment that gives rise to other subpopulations of $2^{\circ}$ TGCs either directly or through a lineage-committed progenitor (SpT) population, while cells within the chorionic plate, chorionic trophoblasts (CTs), give rise to the cells that form the transport interface - SynTs and sinusoidal TGCs (S-TGCs) (42). TS cells stem cells that exclusively contribute to the mouse placenta - can be isolated from the blastocyst (E3.5) or egg cylinder/early streak stage ( E6.5), but this potential is lost soon after $(43,44)$. In the presence of FGF4, these cells proliferate indefinitely when cocultured with mouse embryonic fibroblasts and, upon growth factor withdrawal, spontaneously differentiate into two of the major cell types of the mature placenta: TGCs and their SpT precursors.

A number of transcription factors are known to be important for the allocation of cell lineages within the mouse placenta following implantation, and their genetic inactivation can result in large scale disruptions of placental structure. For example, activating enhancer-binding protein $2 \gamma$ (AP- $2 \gamma)$, which is initially broadly expressed in the mouse blastocyst, becomes restricted to the ExE after E5.5. Disruption of $A p 2 g$ gene expression results in a reduction in $1^{\circ}$ TGC differentiation, a grossly disorganized ExE, and a smaller than normal EPC (45). Estrogen-related receptor $\beta$ (ESRR $\beta$ ) deficiency, on the other hand, causes embryonic lethality at approximately E10.5 (46), when the mouse embryo begins to rely on a well-perfused placenta with a functional circulatory system to fulfill its metabolic needs (47). These embryos fail to vascularize the labyrinth and exhibit large aberrations in the allocation of terminally differentiated cell types, with an overabundance of TGCs and a severe deficit of SpT precursors. This is a recurring theme in many developmental processes, including formation of the placenta, wherein the lack of critical transcriptional regulators results in aberrant proliferation and/or differentiation of lineage-committed precursors. Along these lines, the retinoblastoma tumor suppressor gene $(R b)$ has surprisingly been found to be critical for extraembryonic development (48). Indeed, placentas developing from embryos lacking $R b$ gene expression exhibit continued cell proliferation and a failure to develop a normal labyrinth layer. The critical role of $R b$ in placental development resides

\section{Figure 3}

Transcriptional and epigenetic regulation of trophoblast lineage restriction in the mouse. Critical transcriptional regulators are highlighted in green, and epigenetic regulators are highlighted in blue. Undifferentiated ES cells are depicted on the left along with known transcriptional and epigenetic regulators responsible for the maintenance of stemness in mouse ES cells. TS cells are depicted on the right along with the differentiation pathways that give rise to lineage-committed progenitors (CTs and SpTs) as well as the terminally differentiated cells of the placenta (multinucleated SynTs and TGCs). The factors necessary for the derivation or maintenance of TS cells are indicated along with factors that operate in a lineage- and stage-specific manner.

solely in early progenitors, and its inactivation exclusively in placental cells derived from the ExE and EPC fails to recapitulate the $R b$-null phenotype (49). All additional phenotypes observed in $R b$ null embryos are secondary to the placental defects. Similarly, the paternally imprinted gene mammalian achaete scute homolog 2 (Mash2), which encodes a basic helix-loop-helix (bHLH) transcription factor, is required for the proper formation of all placental cell types (50). In its absence, the chorionic plate - a derivative of the ExE that, along with fetal blood vessels, forms the labyrinth - fails to vascularize, SpTs are lost, and TGC numbers are increased (50). However, chimeric analyses show that Mash2 is required for cell maintenance only in the SpT layer, suggesting that impaired labyrinth formation is a secondary phenomenon (51). Additionally, forkhead box D3-null (Foxd3-null) placentas also contain an excess of TGCs due to an inability of progenitor proliferation and premature differentiation (52). These findings highlight the interdependence of the various differentiation pathways that form the mature placenta.

Transcriptional regulation of uterine invasion. Anchoring the conceptus to the uterus is a critical placental function. In mice, TGCs perform this role, which involves iCTBs in humans. The bHLH transcription factor HAND1 is critical for TGC formation, and HAND1-deficient mouse embryos die in utero between E7.5 and E8.5 $(53,54)$. Both primary and secondary TGCs are affected in these mice, and the invasive capability of $\mathrm{Hand1}^{-/-}$cells in vitro is substantially reduced (55). It has become increasingly apparent that $2^{\circ}$ TGCs can be grouped into at least four subtypes with differing origins, morphologies, locations, and functions (42). Despite this fact, HAND1 appears to be required for the formation of all known TGC subtypes, including $1^{\circ}$ TGCs, suggesting an early stem cell role. Similarly, the bHLH transcription factor stimulated by retinoic acid 13 (Stra13) also promotes TGC formation (56). Interestingly, retinoic acid treatment promotes TGC formation from TS cells apparently by bypassing the SpT intermediates, consistent with the idea that there are various TGC lineages (42). HAND1 activity is subject to competition from other related factors. The dominant-negative HLH genes inhibitor of DNA binding 1 (Id1) and Id2, for example, are expressed only in the mouse chorion (57) and inhibit TGC formation (58). Id family members appear to play an equally important role in governing human trophoblast differentiation (59). Id2 expression decreases as human cytotrophoblasts differentiate into iCTBs, and this process is diminished in the setting of preeclampsia. Constitutive expression of Id 2 in cultured human cytotrophoblasts constrains differentiation and invasion. Similarly, expression of another bHLH antagonist gene, inhibitor of MyoD family a (Imfa), also promotes TGC formation in mice, possibly by inhibiting MASH2 (60). 
TGC and iCTB invasion anchor the mouse and human conceptus, respectively, to the uterus, and the endovascular component of this process enables remodeling of maternal spiral arterioles, thereby establishing blood flow to the placenta (reviewed in ref. 61). A subset of iCTBs and TGCs breaches spiral arterioles and differentiates into an endovascular subtype that replaces the resident maternal endothelium and intercalates within the smooth muscle walls of the vessels. In a fascinating transdifferentiation process, human iCTBs with a primarily epithelial phenotype acquire vascular/endothelial characteristics. The component steps include downregulation of integrin $\alpha_{6} \beta_{4}$ and E-cadherin and upregulation of integrins $\alpha_{V} \beta_{3}$ and $\alpha_{1} \beta_{1}$, VE-cadherin, VCAM- 1 , and PECAM-1 (reviewed in ref. 62). Additionally, iCTBs produce a number of proteins that are involved in extracellular matrix degradation (reviewed in ref. 63). In humans, the transcriptional basis of this tumor-like gene expression program remains largely unknown. One possibility is that these changes are somehow linked to the aforementioned aberrations in chromosome number that are coincident with iCTB differentiation. Given the large-scale gene expression changes observed (M. Gormley, N. Hunkapiller, and S.J. Fisher, unpublished data), epigenetic mechanisms and environmental factors are also likely to be involved. Importantly, this process transforms maternal spiral arterioles into low-pressure conduits. Understanding the molecular underpinnings of endovascular invasion is critical to maternal-fetal medicine. Aberrations of this "physiological transformation" that result in shallow invasion and underperfusion of the fetal unit are part of the placental component of preeclampsia that somehow triggers maternal hypertension and other manifestations of this serious complication of pregnancy. If untreated, this syndrome can progress to the life-threatening condition eclampsia, which is characterized by maternal seizures (reviewed in ref. 64).

Formation of the maternal-fetal transport interface. Glial cells missing-1 (GCM1) is the earliest-acting transcription factor known to function during formation of the mouse placental labyrinth. Its expression in the chorionic plate region marks the first lineagecommitted progenitors destined to differentiate into the multinucleated SynTs that form the interface between maternal and fetal vessels (65). Similar to TGC differentiation, formation of the labyrinth in mice involves the generation of multiple labyrinth-specific subtypes that can be characterized based on marker gene expression and localization. The chorionic plate, which is composed of CTs, is derived from the ExE, while SpTs and most secondary TGCs are derived from the EPC (Figure 2). Clusters of cells within the chorionic plate initiate $\mathrm{Gcm} 1$ gene expression at day E7.5. In its absence, the chorionic plate remains compact, fetal vessels do not invade into the placenta, and similarly to the effect of HAND1 on TGC differentiation, SynT differentiation does not occur. Interestingly, Gcm1 gene expression as well as terminal differentiation within the chorionic plate is dependent on the expression of the Ets-domain transcriptional repressor Ets2 repressor factor (Erf) (66). Erf-null mice fail to induce $G \mathrm{~cm} 1$ gene expression in the chorionic plate and maintain Esrrb expression, thereby inhibiting differentiation of the chorionic plate into the mature labyrinth. Erf-null TS cells exhibit delayed differentiation, maintaining expression of the TS cell marker genes $C d x 2$, Esrrb, and Eomes and expressing reduced levels of the SpT-specific gene trophoblast-specific protein $\alpha$ (Tpbpa; also known as 4311). Erf and Gcm1 expression thus define a population of lineage-committed progenitors destined to form the labyrinth, and its absence precludes SynT differentiation. Another Ets-domain transcription factor gene, Ets2, is also required for early trophoblast differentiation. In its absence, there is substantially reduced CT development and decreased expression of ExE markers (67). Ets2-null TS cells grow more slowly than their WT counterparts and express less $C d x 2$ (68). Required slightly later for formation of the labyrinth, CCAAT/enhancer-binding protein $\alpha$ $(\mathrm{C} / \mathrm{EBP} \alpha)$ and $\mathrm{C} / \mathrm{EBP} \beta$ are coexpressed in the early-gestation chorionic plate and later in trophoblasts of the labyrinthine layer. In placentas lacking both $\mathrm{C} / \mathrm{EBP} \alpha$ and $\mathrm{C} / \mathrm{EBP} \beta$, blood vessels invade the chorion but vessel expansion and development of the labyrinthine layer are impaired (69). Interestingly, in mice, fetal endothelial cells are separated from maternal blood by 3 trophoblast layers: a mononucleated TGC subtype (S-TGCs) and two separate SynT layers (70) (Figure 1, D-F). These cells express unique marker genes and, like TGCs, appear to arise from distinct precursors in the chorion that differentiate along their respective paths before morphogenesis begins. Interestingly, S-TGCs may also derive from the chorionic plate in mice, as opposed to the EPC, highlighting the diverse origin of TGC subtypes (42). In humans, as gestational age advances, the precursor villous CTB ( $\mathrm{VCTB}$ ) layer that underlies the SynT (Figure 1, B and C) becomes discontinuous, which may limit the ability of the human placenta to repair itself.

A major difficulty with attempting to study SynT function is the inability of TS cells to readily form these cells in vitro. Surprisingly, we have demonstrated that the oxygen-sensitive transcriptional regulator HIF actively suppresses SynT formation from TS cells in culture (71). This occurs in an oxygen-independent manner and is due to the modulation of cellular histone deacetylase (HDAC) activity by the HIF family of transcription factors. HIF deficiency, as well as generalized HDAC inhibition, prevents TGC and SpT formation from mouse TS cells and promotes the formation of SynTs (71). This unexpected finding has now made it feasible to study SynT function more reliably in vitro, and studies of the mechanisms involved should yield new insights into key lineage commitment steps necessary for the formation of this critical placental cell type. Additionally, the results of these studies highlight the interrelationship of genetic, epigenetic, and environmental factors in TS cell fate determination (72).

\section{Epigenetic regulation of placental and embryonic development}

Epigenetics refers to heritable alterations of gene expression independent of genomic nucleotide mutations. Epigenetic mechanisms form the foundation of a process termed programming, in which a cellular memory is imposed upon the progeny of lineage-committed precursors to ensure both the acquisition and maintenance of a terminally differentiated state (73). In this context, somatic cells acquire progressively more epigenetic marks as they differentiate. Germ cells and early embryos are capable of resetting these marks - a process termed reprogramming $(74,75)$. The methylation of cytosine residues in CPG dinucleotides is the best-known epigenetic modification; histone posttranslational modifications are another. A veritable alphabet soup of these modifications helps determine higher-order DNA structure by distinguishing heterochromatin, highly compacted gene-poor regions, from euchromatin, relatively decondensed gene-rich regions. The nature of DNA packaging around the nucleosome determines accessibility of the transcriptional machinery to genes (76).

DNA methylation. Epigenetic mediators are increasingly understood to play important roles during early embryonic development (73). With regard to DNA methylation, global patterns inherited 
from both parents are erased at the morula stage $(77,78)$, coincident with early TE differentiation. Thereafter, establishment of the ICM is accompanied by a wave of de novo DNA methylation, which does not occur to the same extent in the TE, an epigenetic disparity that is maintained throughout gestation $(79,80)$. However, recent work suggests that promoter-associated methylation patterns may actually be comparable between embryonic and extraembryonic components, which is consistent with comparable levels of transcriptional activity in each (81). The importance of de novo DNA methylation is highlighted by the fact that genetic inactivation of the methyltransferases responsible for $\mathrm{CpG}$ dinucleotide methylation, DNA methyltransferase $1(D n m t 1)$ and $D n m t 3 b$, is lethal to developing mouse embryos $(82,83)$. Conversely, overexpression of Dnmt1 in transgenic mouse embryos is also lethal. Additionally, Dnmt1 $1^{-/}$mouse ES cells readily differentiate into TGCs under TS cell culture conditions, a phenotype that can be mimicked by culturing WT mouse ES cells in 5-azacytidine, an inhibitor of DNA methylation (84). In this study (84), a genome-wide screen identified the Ets family transcription factor gene E74-like factor 5 (Elf5) as methylated and repressed in ES cells and hypomethylated and expressed in TS cells. ELF5 binds to the Cdx2 and Eomes promoters, inducing their placental expression. Mouse embryos lacking the product of the Elf5 gene form mural TE and implant, but fail to expand the EPC (85). At a molecular level, $C d x 2$ expression is initially established, but subsequently lost by E5.5. CpG-binding protein, a transcriptional activator that specifically recognizes unmethylated $\mathrm{CPG}$ islands, is similarly required for early embryonic development (86). Highlighting the intersection of epigenetic regulatory pathways, impaired methylation in Dnmt3a-/-Dnmt3b-/embryos is accompanied by substantially decreased HDAC activity (87). The importance of the latter molecules was demonstrated by the ability of the HDAC inhibitor trichostatin A to impair mouse ES cell differentiation (88). Consistent with these observations,

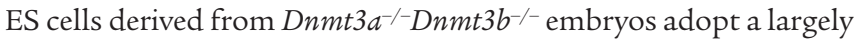
extraembryonic cell fate upon differentiation (87). Conversely, Oct4 expression is aberrantly induced in TS cells in the presence of 5-azacytidine (89). The mouse Oct4 promoter is hypomethylated in ES cells but hypermethylated in TS cells. Importantly, in the placentas of Dnmt1 $1^{-/-}$mice, Oct4 is ectopically expressed (89). This may explain why demethylation induced by systemic 5 -azacytidine administration to pregnant rats results in the formation of smaller placentas, a severely attenuated labyrinth, and an excess of TGCs $(90,91)$. Additional evidence implicating DNA methylation in ExE formation comes from the genetic inactivation of Dnmt3L, a cofactor for the de novo methyltransferases DNMT3A and DNMT3B that helps establish germline methylation patterns $(92,93)$. Dnmt $3 L$ is highly expressed in the chorion, and $D n m t 3 L$ null embryos fail to form a labyrinthine layer, likely due to the loss of Gcm1 expression. Additionally, the SpT layer is reduced, with a concomitant increase in TGCs.

Histone methylation. There are also a large number of proteins with histone methyltransferase activity (94). These proteins are generally important for embryonic and placental development in mice. For example, the absence of the histone H3-K9 methyltransferase ERG-associated protein with SET domain (ESET) results in an inability of mouse embryos to progress beyond the blastocyst stage. Additionally, these embryos exhibit ICM growth defects and fail to give rise to ES cell lines (95). Inactivation of either of the histone methyltransferase genes, G9a or Glp, leads to placental defects due to failed chorioallantoic fusion - the process allow- ing for the attachment of fetal vasculature within the allantois to the developing chorionic plate and SynT layer $(96,97)$. While mice lacking both suppressor of variegation 3-9 homolog 1 (Suv39b1) and Suv $39 h 2$ survive to term, fibroblasts derived from these mice become progressively tetra- and polyploid in culture (98), suggesting that the methylation of pericentric heterochromatin mediated by Suv39h1 and Suv39h2 may play a role in TGC endoreplication. The polycomb group family members embryonic ectoderm development (EED), enhancer of zeste homolog 2 (EZH2), and suppressor of zeste 12 homolog (SUZ12) are responsible for H3-K27 methylation. Ezh2 and Suz12 mutations result in embryonic lethality due to placental defects characterized by failed chorioallantoic attachment $(99,100)$. Eed mutants, on the other hand, exhibit placental defects due to impaired TGC differentiation $(101,102)$. Finally, protein arginine methylation is also necessary for proper formation of the mouse placenta. For example, excess arginine methyltransferase activity decreases TE differentiation in favor of ICM formation (103), while absence of protein arginine methyltransferase 1 (PRMT1) leads to embryonic lethality due to an inability to form the ectoplacental cavity (104).

Histone acetylation. Numerous proteins with HDAC activity have been isolated. The classical HDAC family is divided into two classes based on homology to the related yeast proteins, reduced potassium dependence 3 and Hda1. While class I HDACs (HDAC1, -2, -3 , and -8 ) are found ubiquitously, class II HDACs (HDAC4, -5, -6, $-7,-9,-10$, and -11 ) are expressed in a much more tissue-restricted fashion and play an important role in differentiation $(105,106)$. In addition, the nonclassical HDACs, defined by homology to yeast Silent information regulator 2 (Sir2), are $\mathrm{NAD}^{+}$-dependent HDACs $(107,108)$. While the classical HDACs can be inhibited by trichostatin A, the nonclassical ones cannot. Interestingly, the nonclassical HDACs require $\mathrm{NAD}^{+}$as a cofactor for hydrolyzing target acetyl groups. This link ensures that acetylation of histones or other proteins is tightly linked with cellular $\mathrm{NAD}^{+} / \mathrm{NADH}$ ratios (109). The coupling of cellular energetics with nonclassical HDAC activity could be one mechanism responsible for their ability to affect life span in multiple organisms. Interestingly, the redox-sensitive HDAC sirtuin 1 (Sirt1) has recently been found to associate with HIF- $2 \alpha$ under hypoxic conditions, thereby modulating the activity of this transcription factor (110). Further highlighting the integration of metabolic and epigenetic effectors, global histone acetylation depends on the activity of ATP citrate lyase - the metabolic enzyme that converts citrate into acetyl CoA (111). Although the underlying mechanisms are unclear, the data support a requirement for cellular acetyl CoA production, which, in turn, plays a role in histone acetylation.

Targeted inactivation of multiple HDAC enzymes has been described, with only a few required during early embryonic development (112). In these cases, a specific role for placental HDAC activity has not yet been established. HDAC1 deficiency in mice results in embryonic lethality due to generalized proliferation defects secondary to increased expression of the cell-cycle inhibitors p21 and p27 (113). While HDAC1 is highly expressed in the ExE and EPC, it appears that placental defects do not directly cause the embryonic lethality - with the caveat that tetraploid rescue of $\mathrm{Hdac1}^{-/-}$embryos has not been attempted, an experiment that would prove the point. Similarly, HDAC7 deficiency results in endothelial cell dysfunction and, subsequently, embryonic death without obvious roles in the ICM or TE. The lack of HDAC3 manifests as gastrulation defects that impede further development past 
E9.5 (114). However, pharmacologic inhibition of HDAC activity has profound effects on cell fate specification in TS cells (71), suggesting that there is significant redundancy among individual HDAC family members during the early embryonic period. Offtarget effects of these drugs are also possible.

\section{Metabolic regulation of placental and early embryonic development}

Blastocyst activation, the transition from dormancy to implantation competency, is accompanied by global gene expression profile changes across multiple broad categories, including pathways that regulate the cell cycle, cell signaling, and bioenergetics (115). This suggests that basic metabolic factors, in addition to transcriptional and cell signaling pathways, can be important determinants of successful early embryonic development. For example, following blastocyst activation in mice, there is a shift in metabolic substrates from pyruvate to glucose $(116,117)$. Along these lines, there is a substantial increase in facilitative glucose transporter expression between fertilization and blastocyst formation (118); inactivation of the genes encoding glucose transporter 3 (GLUT3) or GLUT8 results in blastocyst incompetence (119-122). Glucose transporter expression in multiple cell types is under the control of environmental oxygen tension; this regulation is also observed in mouse blastocysts (123). Thus, basic metabolic factors such as glucose and oxygen availability can profoundly affect early embryonic development. Additional nutrients, such as amino acids, also have been shown to regulate early embryonic development in mammals (124).

Early on, investigators found that approximately 5\% $\mathrm{O}_{2}$ (as opposed to $21 \% \mathrm{O}_{2}$ in the atmosphere) recreates the in vivo oxygen environment for mammalian embryonic development - a phenomenon that has been demonstrated for rabbit (125), mouse (126-130), sheep, cow $(131,132)$, and human (133) embryos. Conversely, $21 \% \mathrm{O}_{2}$ consistently decreases the percentage of single-cell embryos developing to blastocysts. Gene expression profiling of mouse blastocysts produced by in vitro fertilization (IVF) and cultured under $21 \% \mathrm{O}_{2}$, as compared with their in vivo counterparts, revealed large-scale gene expression differences that were minimized when the culture conditions were changed to a hypoxic environment (130). Along these lines, culture in lower $\mathrm{O}_{2}$ levels helps maintain human ES cells in an undifferentiated state (134). Importantly, the oviducts and uterine horns of mammals exhibit oxygen tension in the $3 \%$ range, suggesting that fertilization and the early stages of embryonic development take place in physiologically hypoxic environments (135-138).

Clinically, these findings have important implications for assisted reproductive technologies such as IVF. The appropriate oxygen environment for human embryos produced by IVF is also likely to be physiologically hypoxic. Recent data support this concept. Three prospective randomized trials compared the effects of physiological hypoxia $\left(5 \% \mathrm{O}_{2}\right)$ versus room air in terms of embryo development and blastocyst expansion. All found improved human embryonic development in reduced $\mathrm{O}_{2}$ atmospheres and increased birth rates (139-141). Furthermore, culture under hypoxic conditions reduces the rate of whole chromosome aneuploidies in mouse embryos (142), suggesting that the increased rate of genetic abnormalities in IVF-derived embryos (143) may be partially attributable to supraphysiological oxygen exposure with subsequent HIF inactivation, along with ROS-mediated damage.
Following implantation, the first 10-12 weeks of human pregnancy transpires in the absence of significant maternal blood flow to the conceptus. Only after this point do spiral arteries perfuse the placental bed with maternal blood in a pulsatile fashion (144, 145). In primates, plugs of endovascular iCTBs actually block the flow of maternal blood to the placenta during the first trimester $(146,147)$. Direct measurement of $\mathrm{O}_{2}$ tension within the intervillous space and in the exocoelomic fluid surrounding the amniotic sac in humans confirms that these regions are hypoxic, measuring approximately $20 \mathrm{mmHg}$ (approximately 3\%) (148-150). Interestingly, the early human embryonic-placental unit utilizes alternative, phylogenetically ancient (151) metabolic pathways during this period (152). The levels of polyols such as sorbitol, ribitol, and erythritol are much higher in the exocoelomic fluid and amniotic sac than in the maternal circulation. These pathways allow glycolysis to continue without the excess accumulation of lactate, which would otherwise lead to substantial changes in the $\mathrm{pH}$ of the fetal environment. This circuitry also helps maintain an appropriate redox status by replenishing cellular NADPH and, subsequently, reducing glutathione levels.

HIF-1, which is central to cellular hypoxia responses, is a nearly ubiquitous transcription factor complex that regulates many of the known cellular and organismal responses to oxygen deprivation. Under normoxic conditions, the HIF-1 $\alpha$ subunit is constitutively transcribed, translated, and hydroxylated at multiple proline residues by a set of prolyl 4-hydroxylase enzymes. The hydroxylated prolines are recognized by the von Hippel-Lindau (VHL) E3 ubiquitin ligase complex, which targets HIF-1 $\alpha$ for proteasomal degradation (153). HIF-1 $\beta$ (also known as ARNT), which is constitutively stable, is expressed in a nuclear location. This system is finely tuned to sense oxygen tension. Following as few as $5 \mathrm{~min}-$ utes of reoxygenation, most stabilized HIF- $1 \alpha$ is degraded. In contrast, during hypoxia, mitochondria-derived ROS inhibit HIF- $1 \alpha$ hydroxylation, enabling nuclear translocation, heterodimerization with ARNT, and activation of hypoxia-induced genes. We showed that ARNT is critical for development, particularly of the placenta, where oxygen tension regulates cell fate decisions (71, 154). In particular, Arnt ${ }^{-/}$placentas display a grossly disrupted architecture due to reduced progenitor proliferation resulting in impaired vascularization of the labyrinth (154). Furthermore, conditions that produce constitutively active HIF (e.g., inactivation of the genes encoding mouse VHL or prolyl hydroxylase domain-containing protein 2 [PHD2]) also result in embryonic lethality due to impaired placentation $(155,156)$. These findings indicate that precise regulation of HIF levels is critical for normal placentation in vivo. Additionally, we have shown that oxygenindependent induction of HIF activity plays important roles in mediating murine TS cell fate decisions, inhibiting SynT differentiation in favor of TGC formation (71).

The role of HIF-dependent gene expression in human placental development has been much more difficult to resolve, due in large part to the absence of a human TS cell system. The difficulties are compounded by the model systems that are used in their place to investigate oxygen effects, which include human placental cell preparations of various cellular compositions and gestational ages, cell lines, and many different culture conditions. As a result, conflicting data have been published (157). However, most findings support an important regulatory role for cellular metabolic status during placentation. In this context, the dynamic environment in which early placental development takes place suggests 
the need for more physiologically relevant models of human placentation. Additionally, while oxygen tension has been the center of attention, other metabolic factors, such as glucose concentration, need careful evaluation. Standard tissue culture medium contains significantly greater amounts of glucose than found in either maternal or embryonic/fetal blood. Along these lines, we have data showing that altering metabolic substrates other than oxygen can affect mouse TS cell differentiation pathways (H. Choi and E. Maltepe, unpublished data).

\section{Summary and clinical implications}

In summary, the cell-cell interactions at the maternal-fetal interface from implantation onward are a graphic illustration of the unique ability of trophoblasts to integrate the developing embryo/fetus with uterine tissues, which accomplishes an important anchoring function, and with the uterine circulation, which enables perfusion. It is widely appreciated that these connections are a critical component of normal human pregnancy, as defects lead to a spectrum of disorders. Although the causal relationships are unclear, it is possible that, at some level, this spectrum includes certain causes of infertility. Additionally, various overlapping mechanisms could account for a subset of pregnancy losses at early stages and, at later stages, complications that are associated with faulty placentation, such as intrauterine growth restriction and/or preeclampsia. It is generally less well appreciated that trophoblasts integrate the physiology of the developing offspring with that of the intrauterine environment and the mother as a whole. Through their oxygen-sensing capabilities, which are tied to key points of metabolic control, they relay signals that are likely to play important roles during the prenatal period in laying down the foundation of diverse aspects of health manifested over the following decades. As such, we theorize that the placenta, by virtue of its critical structural and functional roles, is a key link in the chain of events that lead to intrauterine programming of adult health. Discovering the molecular mechanisms that underlie these phenomena is the critical and exciting next challenge. We envision that monitoring these pathways could enable better prediction of pregnancy outcomes and real-time assessment of status in terms of maternal and fetal well-being, with therapeutic interventions another interesting possibility.

\section{Acknowledgments}

We are grateful for the excellent graphic design assistance of Joseph J. Hill and to James Cross for his valuable input. The work described in this manuscript was supported by the NIH (HL64597, KO8HL33488, HD030367, HD055764, and HD055638) and the William H. Tooley Funds (Cardiovascular Research Institute, UCSF).

Address correspondence to: Emin Maltepe, Departments of Pediatrics and Biomedical Sciences, Eli and Edythe Broad Center for Regeneration Medicine and Stem Cell Research, Center for Reproductive Sciences, University of California, San Francisco, 513 Parnassus Ave. HSE-1401, Box 1346, San Francisco, CA 94143-1346. Phone: 415.476.9313; Fax: 415.514.0235; E-mail: emin.maltepe@ucsf.edu.
1. Goldenberg RL, Culhane JF, Iams JD, Romero R. Epidemiology and causes of preterm birth. Lancet. 2008;371(9606):75-84.

2. Saigal S, Doyle LW. An overview of mortality and sequelae of preterm birth from infancy to adulthood. Lancet. 2008;371(9608):261-269.

3. Eichenwald EC, Stark AR. Management and outcomes of very low birth weight. $N$ Engl J Med. 2008;358(16):1700-1711.

4. Murphy VE, Smith R, Giles WB, Clifton VL. Endocrine regulation of human fetal growth: the role of the mother, placenta, and fetus. Endocr Rev. 2006;27(2):141-169.

5. Oyama S. The Ontogeny of Information. Developmental Systems and Evolution. Raleigh, NC: Duke University Press; 2000.

6. Genbacev O, Zhou Y, Ludlow JW, Fisher SJ. Regulation of human placental development by oxygen tension. Science. 1997;277(5332):1669-1672.

7. Benirschke K. Remarkable placenta. Clin Anat. 1998;11(3):194-205.

8. Li M, Yee D, Magnuson TR, Smithies O, Caron KM. Reduced maternal expression of adrenomedullin disrupts fertility, placentation, and fetal growth in mice. J Clin Invest. 2006;116(10):2653-2662.

9. Kanayama N, et al. Deficiency in p57Kip2 expression induces preeclampsia-like symptoms in mice. Mol Hum Reprod. 2002;8(12):1129-1135.

10. Irani RA, et al. The detrimental role of angiotensin receptor agonistic autoantibodies in intrauterine growth restriction seen in preeclampsia.J Exp Med. 2009;206(12):2809-2822.

11. Kanasaki K, et al. Deficiency in catechol-Omethyltransferase and 2-methoxyoestradiol is associated with pre-eclampsia. Nature. 2008; 453(7198):1117-1121.

12. Venkatesha $S$, et al. Soluble endoglin contributes to the pathogenesis of preeclampsia. Nat Med. 2006;12(6):642-649.

13. Maynard SE, et al. Excess placental soluble fms-like tyrosine kinase 1 (sFlt1) may contribute to endothelial dysfunction, hypertension, and proteinuria in preeclampsia. J Clin Invest. 2003;111(5):649-658

14. Redman CW, Sargent IL. Latest advances in understanding preeclampsia. Science. 2005;308(5728):1592-1594.

15. Barker DJ. The developmental origins of adult disease. J Am Coll Nutr. 2004;23:588S-595S.

16. Yamanaka Y, Ralston A, Stephenson RO, Rossant J. Cell and molecular regulation of the mouse blastocyst. Dev Dyn. 2006;235(9):2301-2314.

17. Nichols J, et al. Formation of pluripotent stem cells in the mammalian embryo depends on the POU transcription factor Oct4. Cell. 1998;95(3):379-391.

18. Avilion AA, Nicolis SK, Pevny LH, Perez L, Vivian N, Lovell-Badge R. Multipotent cell lineages in early mouse development depend on SOX2 function. Genes Dev. 2003;17:126-140.

19. Mitsui K, et al. The homeoprotein Nanog is required for maintenance of pluripotency in mouse epiblast and ES cells. Cell. 2003;113(5):631-642.

20. Zhang J, et al. Sall4 modulates embryonic stem cell pluripotency and early embryonic development by the transcriptional regulation of Pou5f1. Nat Cell Biol. 2006;8(10):1114-1123.

21. Jiang J, et al. A core Klf circuitry regulates selfrenewal of embryonic stem cells. Nat Cell Biol. 2008;10(3):353-360.

22. Hochedlinger K, Plath K. Epigenetic reprogramming and induced pluripotency. Development. 2009;136(4):509-523.

23. Niwa $\mathrm{H}$, et al. Interaction between Oct $3 / 4$ and $\mathrm{Cd} 2$ determines trophectoderm differentiation. Cell. 2005;123(5):917-929.

24. Strumpf D, et al. Cdx2 is required for correct cell fate specification and differentiation of trophectoderm in the mouse blastocyst. Development. 2005;132(9):2093-2102.

25. Nishioka N, et al. Tead4 is required for specification of trophectoderm in pre-implantation mouse embryos. Mech Dev. 2008;125(3-4):270-283.

26. Yagi $\mathrm{R}$, et al. Transcription factor TEAD4 specifies the trophectoderm lineage at the begin- ning of mammalian development. Development. 2007;134(21):3827-3836.

27. Vassilev A, Kaneko KJ, Shu H, Zhao Y, DePamphilis ML. TEAD/TEF transcription factors utilize the activation domain of YAP65, a Src/Yes-associated protein localized in the cytoplasm. Genes Dev. 2001;15(10):1229-1241.

28. Zhao B, Ye X, Yu J, Li L, Li W, Li S, Lin JD, Wang CY, Chinnaiyan AM, Lai ZC, et al. TEAD mediates YAPdependent gene induction and growth control. Genes Dev. 2008;22(14):1962-1971.

29. Nishioka N, et al. The Hippo signaling pathway components Lats and Yap pattern Tead4 activity to distinguish mouse trophectoderm from inner cell mass. Dev Cell. 2009;16(3):398-410.

30. Russ AP, et al. Eomesodermin is required for mouse trophoblast development and mesoderm formation. Nature. 2000;404(6773):95-99.

31. Rossant J, Cross JC. Placental development: lessons from mouse mutants. Nat Rev Genet. 2001;2(7):538-548.

32. Gonzalez MA, et al. Geminin is essential to prevent endoreduplication and to form pluripotent cells during mammalian development. Genes Dev. 2006;20(14):1880-1884.

33. Zhu W, Chen Y, Dutta A. Rereplication by depletion of geminin is seen regardless of p53 status and activates a G2/M checkpoint. Mol Cell Biol. 2004;24(16):7140-7150.

34. Xouri G, Dimaki M, Bastiaens PI, Lygerou Z. Cdt1 interactions in the licensing process: a model for dynamic spatiotemporal control of licensing. Cell Cycle. 2007;6(13):1549-1552.

35. Melixetian M, et al. Loss of Geminin induces rereplication in the presence of functional p53. J Cell Biol. 2004;165(4):473-482.

36. Geng Y, et al. Cyclin E ablation in the mouse. Cell. 2003;114(4):431-443.

37. Parisi T, et al. Cyclins E1 and E2 are required for endoreplication in placental trophoblast giant cells. EMBO J. 2003;22(18):4794-4803.

38. Kubiak JZ, Tarkowski AK. Electrofusion of mouse 
blastomeres. Exp Cell Res. 1985;157(2):561-566.

39. Nagy A, et al. Embryonic stem cells alone are able to support fetal development in the mouse. Development. 1990;110(3):815-821.

40. Eakin GS, Hadjantonakis AK, Papaioannou VE, Behringer RR. Developmental potential and behavior of tetraploid cells in the mouse embryo. Dev Biol. 2005;288(1):150-159.

41. Weier JF, et al. Human cytotrophoblasts acquire aneuploidies as they differentiate to an invasive phenotype. Dev Biol. 2005;279(2):420-432.

42. Simmons DG, Fortier AL, Cross JC. Diverse subtypes and developmental origins of trophoblast giant cells in the mouse placenta. Dev Biol. 2007:304(2):567-578.

43. Tanaka S, Kunath T, Hadjantonakis AK, Nagy A, Rossant J. Promotion of trophoblast stem cell proliferation by FGF4. Science. 1998;282(5396):2072-2075.

44. Uy GD, Downs KM, Gardner RL. Inhibition of trophoblast stem cell potential in chorionic ectoderm coincides with occlusion of the ectoplacental cavity in the mouse. Development. 2002; 129(16):3913-3924.

45. Auman HJ, Nottoli T, Lakiza O, Winger Q, Donaldson S, Williams T. Transcription factor AP-2gamma is essential in the extra-embryonic lineages for early postimplantation development. Development. 2002;129(11):2733-2747.

46. Luo J, Sladek R, Bader JA, Matthyssen A, Rossant J, Giguere V. Placental abnormalities in mouse embryos lacking the orphan nuclear receptor ERR-beta. Nature. 1997;388(6644):778-782.

47. Maltepe E, Simon MC. Oxygen, genes, and development: an analysis of the role of hypoxic gene regulation during murine vascular development. J Mol Med. 1998;76(6):391-401.

48. Wu L, et al. Extra-embryonic function of Rb is essential for embryonic development and viability. Nature. 2003;421(6926):942-947.

49. Wenzel PL, et al. Rb is critical in a mammalian tissue stem cell population. Genes Dev. 2007;21(1):85-97.

50. Guillemot F, et al. Genomic imprinting of Mash2, a mouse gene required for trophoblast development. Nat Genet. 1995;9(3):235-242.

51. Tanaka M, Gertsenstein M, Rossant J, Nagy A. Mash2 acts cell autonomously in mouse spongiotrophoblast development. Dev Biol. 1997;190(1):55-65

52. Tompers DM, Foreman RK, Wang Q, Kumanova M, Labosky PA. Foxd3 is required in the trophoblast progenitor cell lineage of the mouse embryo. Dev Biol. 2005;285(1):126-137.

53. Riley P, Anson-Cartwright L, Cross JC. The Hand 1 bHLH transcription factor is essential for placentation and cardiac morphogenesis. Nat Genet. 1998;18(3):271-275.

54. Scott IC, Anson-Cartwright L, Riley P, Reda D, Cross JC. The HAND1 basic helix-loop-helix transcription factor regulates trophoblast differentiation via multiple mechanisms. Mol Cell Biol. 2000;20(2):530-541.

55 . Hemberger M, Hughes M, Cross JC. Trophoblast stem cells differentiate in vitro into invasive trophoblast giant cells. Dev Biol. 2004;271(2):362-371.

56. Hughes M, et al. The Hand1, Stra13 and Gcm 1 transcription factors override FGF signaling to promote terminal differentiation of trophoblast stem cells. Dev Biol. 2004;271(1):26-37.

57. Jen Y, Manova K, Benezra R. Each member of the Id gene family exhibits a unique expression pattern in mouse gastrulation and neurogenesis. Dev Dyn. 1997;208(1):92-106.

58. Cross JC, et al. Hxt encodes a basic helix-loop-helix transcription factor that regulates trophoblast cell development. Development. 1995;121(8):2513-2523.

59. Janatpour MJ, et al. Id-2 regulates critical aspects of human cytotrophoblast differentiation, invasion and migration. Development. 2000;127(3):549-558

60. Kraut N, Snider L, Chen CM, TapscottSJ, Groudine M. Requirement of the mouse I-mfa gene for placen- tal development and skeletal patterning. EMBOJ. 1998;17(21):6276-6288.

61. Red-Horse K, et al. Trophoblast differentiation during embryo implantation and formation of the maternal-fetal interface. J Clin Invest. 2004;114(6):744-754

62. Hunkapiller NM, Fisher SJ. Chapter 12. Placental remodeling of the uterine vasculature. Methods Enzymol. 2008;445:281-302.

63. Knofler M. Critical growth factors and signalling pathways controlling human trophoblast invasion. Int J Dev Biol. 2010;54(2-3):269-280.

64. Ilekis JV, Reddy UM, Roberts JM. Preeclampsia-a pressing problem: an executive summary of a National Institute of Child Health and Human Development workshop. Reprod Sci. 2007;14(6):508-523.

65. Anson-Cartwright L, Dawson K, Holmyard D, Fisher SJ, Lazzarini RA, Cross JC. The glial cells missing-1 protein is essential for branching morphogenesis in the chorioallantoic placenta. Nat Genet. 2000;25(3):311-314.

66. Papadaki $\mathrm{C}$, et al. Transcriptional repressor erf determines extraembryonic ectoderm differentiation. Mol Cell Biol. 2007;27(14):5201-5213.

67. Georgiades P, Rossant J. Ets2 is necessary in trophoblast for normal embryonic anteroposterior axis development. Development. 2006;133(6):1059-1068.

68. Wen F, et al. Ets2 is required for trophoblast stem cell self-renewal. Dev Biol. 2007;312(1):284-299.

69. Begay V, Smink J, Leutz A. Essential requirement of CCAAT/enhancer binding proteins in embryogenesis. Mol Cell Biol. 2004;24(22):9744-9751.

70. Simmons DG, Natale DR, Begay V, Hughes M, Leutz A, Cross JC. Early patterning of the chorion leads to the trilaminar trophoblast cell structure in the placental labyrinth. Development. 2008;135(12):2083-2091.

71. Maltepe E, et al. Hypoxia-inducible factordependent histone deacetylase activity determines stem cell fate in the placenta. Development. 2005;132(15):3393-3403.

72. Okazaki K, Maltepe E. Oxygen, epigenetics and stem cell fate. Regen Med. 2006;1(1):71-83.

73. Hemberger M, Dean W, Reik W. Epigenetic dynamics of stem cells and cell lineage commitment: digging Waddington's canal. Nat Rev Mol Cell Biol. 2009;10(8):526-537.

74. Sasaki H, Matsui Y. Epigenetic events in mammalian germ-cell development: reprogramming and beyond. Nat Rev Genet. 2008;9(2):129-140.

75. Surani MA, Hayashi K, Hajkova P. Genetic and epigenetic regulators of pluripotency. Cell. 2007;128(4):747-762.

76. Khorasanizadeh S. The nucleosome: from genomic organization to genomic regulation. Cell. 2004;116(2):259-272

77. Monk M, Boubelik M, Lehnert S. Temporal and regional changes in DNA methylation in the embryonic, extraembryonic and germ cell lineages during mouse embryo development. Development. 1987;99(3):371-382.

78. Kafri T, et al. Developmental pattern of gene-specific DNA methylation in the mouse embryo and germ line. Genes Dev. 1992;6(5):705-714.

79. Chapman V, Forrester L, Sanford J, Hastie N, Rossant $\mathrm{J}$. Cell lineage-specific undermethylation of mouse repetitive DNA. Nature. 1984;307(5948):284-286.

80. Rossant J, Sanford JP, Chapman VM, Andrews GK. Undermethylation of structural gene sequences in extraembryonic lineages of the mouse. Dev Biol. 1986;117(2):567-573

81. Farthing CR, et al. Global mapping of DNA methylation in mouse promoters reveals epigenetic reprogramming of pluripotency genes. PLOS Genet. 2008;4(6):e1000116.

82. Okano M, Bell DW, Haber DA, Li E. DNA methyltransferases Dnmt3a and Dnmt3b are essential for de novo methylation and mammalian development. Cell. 1999;99(3):247-257.

83. Li E, Bestor TH, Jaenisch R. Targeted mutation of the DNA methyltransferase gene results in embryonic lethality. Cell. 1992;69(6):915-926.

84. Ng RK, et al. Epigenetic restriction of embryonic cell lineage fate by methylation of Elf5. Nat Cell Biol. 2008;10(11):1280-1290

85. Donnison M, Beaton A, Davey HW, Broadhurst R, L'Huillier P, Pfeffer PL. Loss of the extraembryonic ectoderm in Elf5 mutants leads to defects in embryonic patterning. Development. 2005;132(10):2299-2308.

86. Carlone DL, et al. Reduced genomic cytosine methylation and defective cellular differentiation in embryonic stem cells lacking CpG binding protein. Mol Cell Biol. 2005;25(12):4881-4891.

87. Jackson M, et al. Severe global DNA hypomethylation blocks differentiation and induces histone hyperacetylation in embryonic stem cells. Mol Cell Biol. 2004;24(20):8862-8871.

88. Lee JH, Hart SR, Skalnik DG. Histone deacetylase activity is required for embryonic stem cell differentiation. Genesis. 2004;38(1):32-38

89. Hattori $\mathrm{N}$, et al. Epigenetic control of mouse Oct-4 gene expression in embryonic stem cells and trophoblast stem cells. J Biol Chem. 2004;279(17):17063-17069.

90. Serman L, et al. The impact of 5-azacytidine on placental weight, glycoprotein pattern and proliferating cell nuclear antigen expression in rat placenta. Placenta. 2007;28(8-9):803-811.

91. Vlahovic M, Bulic-Jakus F, Juric-Lekic G, Fucic A, Maric S, Serman D. Changes in the placenta and in the rat embryo caused by the demethylating agent 5-azacytidine. Int J Dev Biol. 1999;43(8):843-846.

92. Hata K, Okano M, Lei H, Li E. Dnmt3L cooperates with the Dnmt3 family of de novo DNA methyltransferases to establish maternal imprints in mice. Development. 2002;129(8):1983-1993.

93. Kaneda M, et al. Essential role for de novo DNA methyltransferase Dnmt3a in paternal and maternal imprinting. Nature. 2004;429(6994):900-903.

94. Lachner M, Jenuwein T. The many faces of histone lysine methylation. Curr Opin Cell Biol. 2002;14(3):286-298.

95. Dodge JE, Kang YK, Beppu H, Lei H, Li E. Histone H3-K9 methyltransferase ESET is essential for early development. Mol Cell Biol. 2004;24(6):2478-2486.

96. Tachibana M, et al. G9a histone methyltransferase plays a dominant role in euchromatic histone H3 lysine 9 methylation and is essential for early embryogenesis. Genes Dev. 2002;16(14):1779-1791.

97. Tachibana M, et al. Histone methyltransferases G9a and GLP form heteromeric complexes and are both crucial for methylation of euchromatin at H3-K9. Genes Dev. 2005;19(7):815-826.

98. Peters AH, et al. Loss of the Suv39h histone methyltransferases impairs mammalian heterochromatin and genome stability. Cell. 2001;107(3):323-337.

99. Pasini D, Bracken AP, Jensen MR, Lazzerini Denchi E, Helin K. Suz12 is essential for mouse development and for EZH2 histone methyltransferase activity. EMBO J. 2004;23(20):4061-4071.

100. O'Carroll D, Erhardt S, Pagani M, Barton SC, Surani MA, Jenuwein $\mathrm{T}$. The polycomb-group gene Ezh2 is required for early mouse development. Mol Cell Biol. 2001;21(13):4330-4336.

101. Wang J, et al. Imprinted $X$ inactivation maintained by a mouse Polycomb group gene. Nat Genet. 2001;28(4):371-375.

102.Wang J, Mager J, Schnedier E, Magnuson T. The mouse PcG gene eed is required for Hox gene repression and extraembryonic development. Mamm Genome. 2002;13(9):493-503.

103.Torres-Padilla ME, Parfitt DE, Kouzarides T, Zernicka-Goetz M. Histone arginine methylation regulates pluripotency in the early mouse embryo. 
Nature. 2007;445(7124):214-218.

104. Pawlak MR, Scherer CA, Chen J, Roshon MJ, Ruley HE. Arginine $\mathrm{N}$-methyltransferase 1 is required for early postimplantation mouse development, but cells deficient in the enzyme are viable. Mol Cell Biol. 2000;20(13):4859-4869.

105. Bertos NR, Wang AH, Yang XJ. Class II histone deacetylases: structure, function, and regulation. Biochem Cell Biol. 2001;79(3):243-252.

106. de Ruijter AJ, van Gennip AH, Caron HN, Kemp S, van Kuilenburg AB. Histone deacetylases (HDACs): characterization of the classical HDAC family. Biochem J. 2003;370(pt 3):737-749.

107. Frye RA. Characterization of five human cDNAs with homology to the yeast SIR2 gene: Sir2-like proteins (sirtuins) metabolize NAD and may have protein ADP-ribosyltransferase activity. Biochem Biophys Res Commun. 1999;260(1):273-279.

108. Frye RA. Phylogenetic classification of prokaryotic and eukaryotic Sir2-like proteins. Biochem Biophys Res Commun. 2000;273(2):793-798.

109. Denu JM. Linking chromatin function with metabolic networks: Sir2 family of NAD(+)-dependent deacetylases. Trends Biochem Sci. 2003;28(1):41-48.

110.Dioum EM, et al. Regulation of hypoxia-inducible factor 2alpha signaling by the stressresponsive deacetylase sirtuin 1 . Science. 2009; 324(5932):1289-1293.

111.Wellen KE, Hatzivassiliou G, Sachdeva UM, Bui TV, Cross JR, Thompson CB. ATP-citrate lyase links cellular metabolism to histone acetylation. Science. 2009;324(5930):1076-1080

112. Haberland M, Montgomery RL, Olson EN. The many roles of histone deacetylases in development and physiology: implications for disease and therapy. Nat Rev Genet. 2009;10(1):32-42.

113. Lagger $\mathrm{G}$, et al. Essential function of histone deacetylase 1 in proliferation control and CDK inhibitor repression. EMBO J. 2002;21(11):2672-2681.

114.Montgomery RL, et al. Maintenance of cardiac energy metabolism by histone deacetylase 3 in mice. J Clin Invest. 2008;118(11):3588-3597.

115. Hamatani $\mathrm{T}$, et al. Global gene expression analysis identifies molecular pathways distinguishing blastocyst dormancy and activation. Proc Natl Acad Sci US A. 2004;101(28):10326-10331.

116.Spindler RE, Renfree MB, Gardner DK. Carbohydrate uptake by quiescent and reactivated mouse blastocysts. J Exp Zool. 1996;276(2):132-137.

117. Holmes PV, Bergstrom S. Induction of blastocyst implantation in mice by cyclic AMP. J Reprod Fertil. 1975;43(2):329-332.

118. Morita Y, Tsutsumi O, Hosoya I, Taketani Y, Oka Y, Kato T. Expression and possible function of glucose transporter protein GLUT1 during preimplantation mouse development from oocytes to blastocysts. Biochem Biophys Res Commun. 1992;188(1):8-15.

119. Ganguly A, et al. Glucose transporter isoform-3 mutations cause early pregnancy loss and fetal growth restriction. Am J Physiol Endocrinol Metab. 2007;292(5):E1241-E1255.

120.Pantaleon M, Harvey MB, Pascoe WS, James DE, Kaye PL. Glucose transporter GLUT3: ontogeny, targeting, and role in the mouse blastocyst. Proc Natl Acad Sci U S A. 1997;94(8):3795-3800.

121.Pinto AB, Carayannopoulos MO, Hoehn A, Dowd L, Moley KH. Glucose transporter 8 expression and translocation are critical for murine blastocyst survival. Biol Reprod. 2002;66(6):1729-1733.

122. Carayannopoulos MO, et al. GLUT8 is a glucose transporter responsible for insulin-stimulated glucose uptake in the blastocyst. Proc Natl Acad SciUS A.
2000;97(13):7313-7318.

123. Kind KL, Collett RA, Harvey AJ, Thompson JG. Oxygen-regulated expression of GLUT-1, GLUT-3, and VEGF in the mouse blastocyst. Mol Reprod Dev. 2005;70(1):37-44.

124. Cross JC, and Mickelson L. Nutritional influences on implantation and placental development. Nutr Rev. 2006;64(5 Pt 2):S12-S18; discussion S72-S91.

125. Li J, Foote RH. Culture of rabbit zygotes into blastocysts in protein-free medium with one to twenty per cent oxygen. J Reprod Fertil. 1993;98(1):163-167.

126. Quinn P, Harlow GM. The effect of oxygen on the development of preimplantation mouse embryos in vitro. J Exp Zool. 1978;206(1):73-80.

127. Pabon JEJr, Findley WE, Gibbons WE. The toxic effect of short exposures to the atmospheric oxygen concentration on early mouse embryonic development. Fertil Steril. 1989;51(5):896-900.

128. Umaoka Y, Noda Y, Narimoto K, Mori T. Effects of oxygen toxicity on early development of mouse embryos. Mol Reprod Dev. 1992;31(1):28-33.

129.Eppig JJ, Wigglesworth K. Factors affecting the developmental competence of mouse oocytes grown in vitro: oxygen concentration. Mol Reprod Dev. 1995;42(4):447-456.

130. Rinaudo PF, Giritharan G, Talbi S, Dobson AT, Schultz RM. Effects of oxygen tension on gene expression in preimplantation mouse embryos. Fertil Steril. 2006;86(Suppl 4):1252-1265, 1265.e1-1265.e36.

131. Thompson JG, Simpson AC, Pugh PA, Donnelly PE, Tervit HR. Effect of oxygen concentration on in-vitro development of preimplantation sheep and cattle embryos. J Reprod Fertil. 1990;89(2):573-578.

132. Bernardi ML, Flechon JE, Delouis C. Influence of culture system and oxygen tension on the development of ovine zygotes matured and fertilized in vitro. J Reprod Fertil. 1996;106(2):161-167.

133.Catt JW, Henman M. Toxic effects of oxygen on human embryo development. Hum Reprod. 2000;15(Suppl 2):199-206.

134.Ezashi T, Das P, Roberts RM. Low $\mathrm{O} 2$ tensions and the prevention of differentiation of hES cells. Proc Natl Acad Sci U S A. 2005;102(13):4783-4788.

135. Fischer B, Bavister BD. Oxygen tension in the oviduct and uterus of rhesus monkeys, hamsters and rabbits. J Reprod Fertil. 1993;99(2):673-679.

136.Kaufman DL, Mitchell JA. Intrauterine oxygen tension during the oestrous cycle in the hamster: patterns of change. Comp Biochem Physiol Comp Physiol. 1994;107(4):673-678.

137. Mitchell JA, Yochim JM. Measurement of intrauterine oxygen tension in the rat and its regulation by ovarian steroid hormones. Endocrinology. 1968;83(4):691-700.

138.Van Blerkom J, Antczak M, Schrader R. The developmental potential of the human oocyte is related to the dissolved oxygen content of follicular fluid: association with vascular endothelial growth factor levels and perifollicular blood flow characteristics. Hum Reprod. 1997;12(5):1047-1055.

139. Kovacic B, Vlaisavljevic V. Influence of atmospheric versus reduced oxygen concentration on development of human blastocysts in vitro: a prospective study on sibling oocytes. Reprod Biomed Online. 2008;17(2):229-236.

140.Waldenstrom U, Engstrom AB, Hellberg D, Nilsson $\mathrm{S}$. Low-oxygen compared with high-oxygen atmosphere in blastocyst culture, a prospective randomized study. Fertil Steril. 2009;91(6):2461-2465.

141. Meintjes $\mathrm{M}$, et al. A controlled randomized trial evaluating the effect of lowered incubator oxygen tension on live births in a predominantly blastocyst transfer program. Hum Reprod. 2009;24(2):300-307.
142. Munne S, Grifo J, Cohen J, Weier HU. Chromosome abnormalities in human arrested preimplantation embryos: a multiple-probe FISH study. Am J Hum Genet. 1994;55(1):150-159.

143. Bonduelle M, Aytoz A, Van Assche E, Devroey P, Liebaers I, Van Steirteghem A. Incidence of chromosomal aberrations in children born after assisted reproduction through intracytoplasmic sperm injection. Hum Reprod. 1998;13(4):781-782.

144.Burton GJ, Jauniaux E, Watson AL. Maternal arterial connections to the placental intervillous space during the first trimester of human pregnancy: the Boyd collection revisited. Am J Obstet Gynecol. 1999;181(3):718-724.

145.Jaffe R, Jauniaux E, Hustin J. Maternal circulation in the first-trimester human placenta-myth or reality? Am J Obstet Gynecol. 1997;176(3):695-705.

146. Enders AC, Blankenship TN. Modification of endometrial arteries during invasion by cytotrophoblast cells in the pregnant macaque. Acta Anat (Basel). 1997;159(4):169-193.

147. Enders AC, King BF. Early stages of trophoblastic invasion of the maternal vascular system during implantation in the macaque and baboon. Am J Anat. 1991;192(4):329-346.

148. Rodesch F, Simon P, Donner C, Jauniaux E. Oxygen measurements in endometrial and trophoblastic tissues during early pregnancy. Obstet Gynecol. 1992;80(2):283-285.

149.Jauniaux E, Watson A, Ozturk O, Quick D, Burton $\mathrm{G}$. In-vivo measurement of intrauterine gases and acid-base values early in human pregnancy. Hum Reprod. 1999;14(11):2901-2904.

150.Jauniaux E, Watson AL, Hempstock J, Bao YP, Skepper JN, Burton GJ. Onset of maternal arterial blood flow and placental oxidative stress. A possible factor in human early pregnancy failure. Am J Pathol. 2000;157(6):2111-2122.

151.Morse DE, Horecker BL. The mechanism of action of aldolases. Adv Enzymol Relat Areas Mol Biol. 1968;31:125-181.

152.Jauniaux E, Hempstock J, Teng C, Battaglia FC, Burton GJ. Polyol concentrations in the fluid compartments of the human conceptus during the first trimester of pregnancy: maintenance of redox potential in a low oxygen environment. J Clin Endocrinol Metab. 2005;90(2):1171-1175.

153. Kaelin WG Jr, Ratcliffe PJ. Oxygen sensing by metazoans: the central role of the HIF hydroxylase pathway. Mol Cell. 2008;30(4):393-402.

154.Adelman DM, Gertsenstein M, Nagy A, Simon MC, Maltepe E. Placental cell fates are regulated in vivo by HIF-mediated hypoxia responses. Genes Dev. 2000;14(24):3191-3203.

155.Gnarra JR, et al. Defective placental vasculogenesis causes embryonic lethality in VHL-deficient mice. Proc Natl Acad Sci U S A. 1997;94(17):9102-9107.

156. Takeda K, Ho VC, Takeda H, Duan LJ, Nagy A, Fong GH. Placental but not heart defects are associated with elevated hypoxia-inducible factor $\{$ alpha\} levels in mice lacking prolyl hydroxylase domain protein 2. Mol Cell Biol. 2006;26(22):8336-8346.

157. Pringle KG, Kind KL, Sferruzzi-Perri AN, Thompson JG, Roberts CT. Beyond oxygen: complex regulation and activity of hypoxia inducible factors in pregnancy [published online ahead of print November 19, 2009]. Hum Reprod Update. doi:10.1093/humupd/dmp046.

158.Robbins J, Skrzypczynska K, Zeldovich V, Kapidzic M, and Bakardjiev A. Placental syncytiotrophoblast constitutes a major barrier to vertical transmission of Listeria monocytogenes. PLoS Pathog. 2010;6(1):e1000732. 